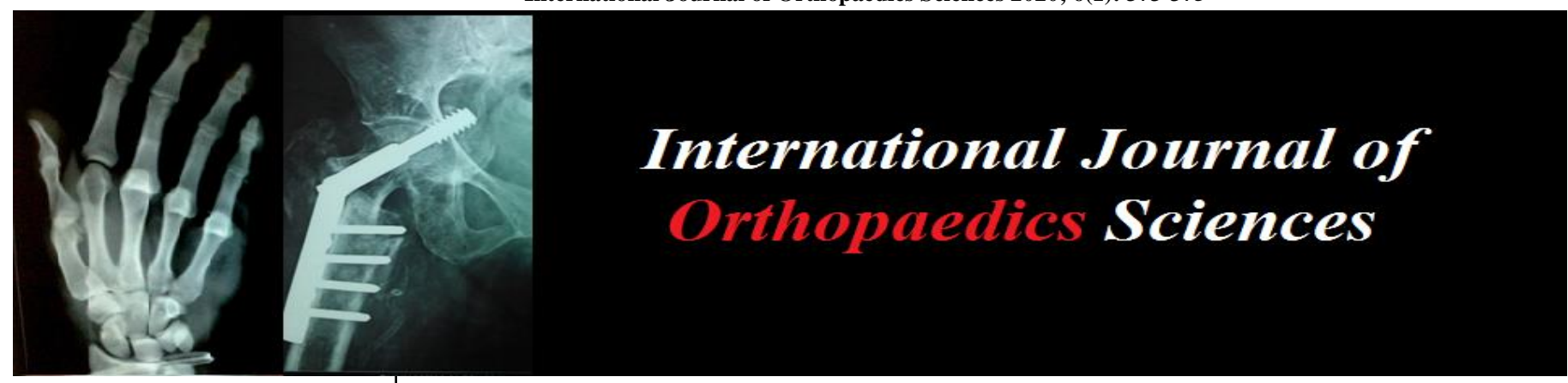

E-ISSN: 2395-1958

P-ISSN: 2706-6630

IJOS 2020; 6(1): 373-375

(C) 2020 IJOS

www.orthopaper.com

Received: 13-11-2019

Accepted: 17-12-2019

Dr. Syed Avad Hussain Junior Resident, Department of Orthopaedics, Sri Siddhartha Medical College, B.H. Road,

Tumkur, Karnataka, India

Dr. Kiran Kalaiah

Professor and HOD, Department of Orthopaedics, Sri Siddhartha

Medical College, B.H. Road,

Tumkur, Karnataka, India

Dr. Baibhav Kumar Agarwal Junior Resident, Department of Orthopaedics, Sri Siddhartha

Medical College, B.H. Road,

Tumkur, Karnataka, India
Corresponding Author: Dr. Syed Avad Hussain Junior Resident, Department of Orthopaedics, Sri Siddhartha Medical College, B.H. Road, Tumkur, Karnataka, India

\section{Functional outcome of proximal third tibial fractures with intramedullary tibial locking nail and poller screws}

\author{
Dr. Syed Avad Hussain, Dr. Kiran Kalaiah and Dr. Baibhav Kumar \\ Agarwal
}

DOI: https://doi.org/10.22271/ortho.2020.v6.i1g.1892

\section{Abstract}

Background: Non-articular fractures of the proximal third of the tibia account for 5 to $11 \%$ of tibial shaft injuries. Closed management often leads to varus malunion, especially when the fibula is intact. Although intramedullary nailing may lead to valgus malunion, it can be useful for stabilising fractures with proximal fragments longer than 5 to $6 \mathrm{~cm}$. Intramedullary nailing for metaphyseal tibial fractures with a short proximal fragment is associated with an increased risk of frontal- and sagittal-plane malalignment. This can be solved by the use of blocking screws or Poller screws.

Methods: 20 men and 15 women aged 20 to 60 (mean, 35.4) years underwent intramedullary nailing supplemented with Poller screws for acutely displaced fracture. $90 \%$ of the fractures were caused by road traffic accidents. 29 cases had closed fractures and 6 had grade I or II compound fractures. Clinical and radiological outcome was evaluated.

Results: In 32 cases, healing occurred after a mean of 4.2 (range, 3-9) months. In 1 case, there was nonunion, which was resolved by bone grafting. One case was mal-united. 32 patients had recovered a full range of knee motion $\left(0^{\circ}-130^{\circ}\right)$, and the remaining 3 patients attained flexion of $0^{\circ}$ to $90^{\circ}$. According to the knee rating scale of the Hospital for Special Surgery, outcome was excellent in 32 patients, good in 2 and poor in 1 at final follow up. Preoperatively, of the 35 cases, 20 were varus, 15 were valgus. The range of varus to valgus was $+22^{\circ}$ to $-10^{\circ}$. Postoperatively, 34 cases had $<5^{\circ}$ of varus or valgus malalignment, and only one developed a varus of $+8^{\circ}$.

Conclusions: Poller screws help maintain fixation of intramedullary nailing and alignment of fractures of proximal third tibia.

Keywords: Proximal tibia extra articular tibial fractures, intra medullary nailing; treatment outcome

\section{Introduction}

Non-articular fractures of the proximal third of the tibia account for 5 to $11 \%$ of tibial shaft injuries. Closed management often leads to varus malunion, especially when the fibula is intact. Although intramedullary nailing may lead to valgus malunion, it can be useful for stabilising fractures with proximal fragments longer than 5 to $6 \mathrm{~cm}^{[1]}$. Intramedullary nailing for metaphyseal tibial fractures with a short proximal fragment (unlike diaphyseal tibial fractures) is associated with an increased risk of frontal- and sagittal-plane malalignment ${ }^{[2-5]}$. This may be attributed to an inaccurate entry site or both displacing muscular forces and residual instability ${ }^{[2]}$. In addition, the large difference between the size of the implant and the metaphyseal diameter increases the risk of malalignment. In the absence of metaphyseal cortex contact, the nail may translate along the interlocking screws, owing to the play between the screws and the nail holes. This can be solved by the use of blocking screws or Poller screws ${ }^{[6-}$ 9]. Poller screws decrease the width of the medullary cavity, guide and block the nail in the centre of the widened metaphyseal area, and increase the mechanical stiffness of the bone implant construct ${ }^{[10]}$. We therefore evaluated outcome of intramedullary nailing supplemented with Poller screws for proximal tibia fractures.

\section{Methods}

Patients admitted to SSMC, Tumkur form June 2018 to December 2019 diagnosed with 
fracture proximal third tibia were prospectively observed and included in the study group.

20 men and 15 women aged 20 to 60 (mean, 35.4) years underwent intramedullary nailing supplemented with Poller screws for acutely displaced fracture. $90 \%$ of the fractures were caused by road traffic accidents. 29 cases had closed fractures and 6 had grade I or II compound fractures. According to the Gustilo Anderson classification soft tissue injuries in open fractures $(n=6)$ were classified. Patients with tibial fractures with the proximal fragment $<6 \mathrm{~cm}$, proximal intra-articular tibial fractures, non-displaced fractures and medically unfit patients were excluded from the study.

The mean length of the proximal fragment was $9.5 \mathrm{~cm}$. The operations were performed within 48 hours of injury in all cases. Stainless steel interlocking nails were used, the most common size being $10-\mathrm{mm}$ in diameter. Locking cortical screws of $3.5 \mathrm{~mm}$ or $4.5 \mathrm{~mm}$ were used for blocking depending on the size of the nail used. All nails were high bend nails with a bend of $11^{\circ}$ near the proximal tip of the nail. Poller screws were used to maintain alignment or to improve the stability of the bone-implant complex or to control the nail during insertion. In all cases, 1 Poller screw was placed on the concave side of the deformity in AP view. Additional poller screw were placed when required.

Intra-operatively, the knee was kept in a flexed position on a well-padded knee rest. Temporary Poller wires were fixed on the opposite side of the apex of deformity in both anteroposterior and lateral views under image intensifier guidance. After cutting the patellar tendon at midline, a high entry point was taken with an awl. A high bend unreamed nail of appropriate size was inserted slowly and negotiated with the Poller wires. The nail was locked in a semi-extended position. Poller wires were then exchanged with permanent cortical screws.

Postoperatively, mobilisation was allowed on day 2. Static and dynamic quadriceps exercises and partial weight-bearing were allowed for 6 to 8 weeks. Thereafter, weight-bearing was increased gradually, depending on the absence of pain and radiographic evidence of bone union. Patients were evaluated using to the Hospital for Special Surgery knee rating scale ${ }^{[11]}$.
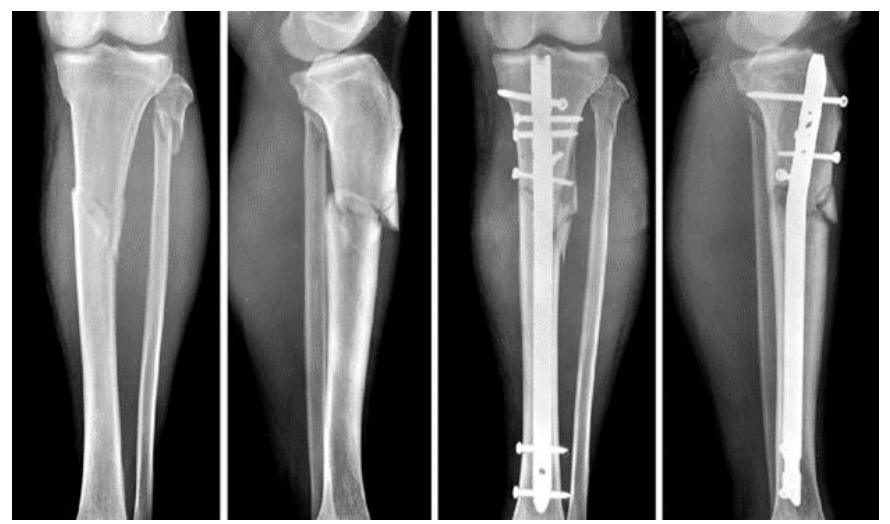

Fig 1: Pre op and Post op X-rays

Patients were followed up at intervals of 6 to 8 weeks for a year, and 6 monthly thereafter. Neurovascular condition, alignment, and functions of the affected limb were assessed. Alignment and deformity was calculated by drawing the anatomic axis of tibia in both proximal and distal fragments on radiographs. The amounts of varus/valgus and procurvatum/recurvatum were then calculated. Varus and procurvatum angulation were expressed as positive values, and valgus and recurvatum as negative values. Healing was defined as the ability to bear full weight without pain and support, with callus bridging in 3 of 4 cortices on radiographs.

\section{Results}

Patients were followed up for a mean period of 6 months. All 35 cases achieved bone union eventually. In 32 cases, healing occurred after a mean of 4.2 (range, 3-9) months. In 1 case, there was non-union, which was resolved by bone grafting. One case was mal-united. 32 patients had recovered a full range of knee motion $\left(0^{\circ}-130^{\circ}\right)$, and the remaining 3 patients attained flexion of $0^{\circ}$ to $90^{\circ}$. All patients were able to perform activities of daily living and walk with full weight bearing and without a limp or shortening.

According to the knee rating scale of the Hospital for Special Surgery, outcome was excellent in 32 patients, good in 2 and poor in 1 at final follow up. Preoperatively, of the 35 cases, 20 were varus, 15 were valgus. The range of varus to valgus was $+22^{\circ}$ to $-10^{\circ}$. Postoperatively, 34 cases had $<5^{\circ}$ of varus or valgus malalignment, and only one developed a varus of $+8^{\circ}$. Preoperatively, of the 35 cases, 31 had procurvatum, 4 had recurvatum. The range of procurvatum to recurvatum deformity was $+7^{\circ}$ to $-16^{\circ}$.

Postoperatively, 32 cases had no deformity, 2 had a deformity of $<3^{\circ}$, and 1 had a deformity of $4^{\circ}$ to $6^{\circ}$. None of the nails or screws was broken. All patients had regained full quadriceps strength, with no ligamentous instability or flexion deformity. Postoperative complications included anterior knee joint pain $(n=4)$ and superficial infections $(n=1)$, which was treated with oral analgesic, anti-inflammatory drugs, local debridement and use of antibiotic impregnated beads.

\section{Discussion}

Our results were similar to those reported in other studies ${ }^{[12-}$ ${ }^{13]}$. Intramedullary nailing for fractures of the proximal third of the tibial shaft has a high rate of malalignment ${ }^{[2]}$. Apex anterior and valgus malalignment and anterior displacement of the proximal fragment are the most common deformities. Sagittal-plane deformities may be caused by the

pull of the patellar tendon, the pull of the anterior compartment muscles, the lack of a posterior cortex, the 'wedge effect' of the bent nail in the distal fragment, a medial starting point to the area of narrow anteroposterior diameter of the proximal tibia, and a distal starting point for nail insertion. Coronal-plane deformities may be caused by a medial starting point, a laterally directed nail insertion angle, and the pull of the lateral compartment muscles. To achieve anatomic reduction, several technical modifications for standard intramedullary nailing have been described to overcome these problems.

In a review of 133 tibial fractures treated with intramedullary nails ${ }^{2}$, proximal third fractures resulted in a significantly higher rate of tibial malalignment than middle or distal third fractures. This was due to the lack of a sufficiently long posterior cortex in the proximal fragment ${ }^{2}$. A neutral to slightly lateral entrance angle for nail insertion should be used for proximal third tibial fractures ${ }^{[2]}$.

The use of blocking screws to supplement intramedullary nailing for metaphyseal femoral and tibial fractures enables control of angular deformity ${ }^{[12]}$ and increases stability of fixation ${ }^{[10]}$.

Poller screws act via a 3-point fixation principle to nullify the forces of muscle and ligament pull and narrow the metaphysis play. Additional Poller screws in the concave side can nullify tissue tension when they are placed close to the center of 
rotation of angulation (CORA), adjacent to the nail track, and perpendicular to the deformity plane. Precautions should be taken not to apply the Poller screws away from the CORA or on the convex side ${ }^{[14]}$. The guidelines include: (1) taking a high entry point (if a low entry point is taken, a proximal Poller screw will have to be added); (2) using a proper size high bend undreamed nail; (3) placing the nail co-axially with the long axis of tibia; (4) accounting for the nail bend distance; and (5) applying a second screw to avoid posterior translation. Poller screws are not just blocking screws but tools of reduction. If the entry point is too high or too low in the lateral view, a second Poller should be added in the anterior distal or posterior proximal part of the fracture.

\section{Conclusion}

Poller screws help maintain fixation of intramedullary nailing and alignment of fractures of proximal third tibia.

\section{Acknowledgements}

We thank our colleagues from Sri Siddhartha Academy of Higher Education who provided insight and expertise that greatly assisted the research. We thank faculty of Department of orthopaedics, Sri Siddhartha medical college, affiliated to Sri Siddhartha Academy of Higher Education for assistance and for comments that greatly improved the manuscript.

\section{References}

1. Bono CM, Levine RG, Rao JP, Behrens FF. Nonarticular proximal tibia fractures: treatment options and decision making. J Am Acad Orthop Surg. 2001; 9:176-86.

2. Freedman EL, Johnson EE. Radiographic analysis of tibial fracture malalignment following intramedullary nailing. Clin Orthop Relat Res. 1995; 315:25-33.

3. Ahlers $\mathbf{J}$, von Issendorff WD. Incidence and causes of malalignment following tibial intramedullary nailing [in German]. Unfallchirurgie. 1992; 18:31-6.

4. Henley MB, Meier M, Tencer AF. Influences of some design parameters on the biomechanics of the unreamed tibial intramedullary nail. J Orthop Trauma. 1993; 7:3119.

5. Tornetta P 3rd, Collins E. Semiextended position for intramedullary nailing of the proximal tibia. Clin Orthop Relat Res. 1996; 328:185-9.

6. Krettek C, Schandelmaier P, Rudolf J, Tscherne H. Current status of surgical technique for unreamed nailing of tibial shaft fractures with the UTN (unreamed tibia nail) [in German]. Unfallchirurg. 1994; 97:575-99.

7. Krettek C, Schulte-Eistrup S, Schandelmaier P, Rudolf J, Tscherne H. Osteosynthesis of femur shaft fractures with the unreamed AO-femur nail. Surgical technique and initial clinical results standard lock fixation [in German]. Unfallchirurg. 1994; 97:549-67.

8. Krettek C, Schandelmaier P, Tscherne H. Nonreamed interlocking nailing of closed tibial fractures with severe soft tissue injury. Clin Orthop Relat Res. 1995; 315:3447.

9. Krettek C, Rudolf J, Schandelmaier P, Guy P, Konemann $\mathrm{B}$, Tscherne $\mathrm{H}$. Unreamed intramedullary nailing of femoral shaft fractures: operative technique and early clinical experience with the standard locking option. Injury. 1996; 27:233-54.

10. Krettek C, Miclau T, Schandelmaier P, Stephan C, Mohlmann U, Tscherne $\mathrm{H}$. The mechanical effect of blocking screws ("Poller screws") in stabilizing tibia fractures with short proximal or distal fragments after insertion of small-diameter intramedullary nails. J Orthop Trauma. 1999; 13:550-3.

11. Insall JN. Surgery of the knee. New York: Churchill Livingstone, 1984.

12. Krettek C, Stephan C, Schandelmaier P, Richter M, Pape HC, Miclau T. The use of Poller screws as blocking screws in stabilising tibial fractures treated with small diameter intramedullary nails. J Bone Joint Surg Br. 1999; 81:963-8.

13. Ricci WM, O’Boyle M, Borrelli J, Bellabarba C, Sanders R. Fractures of proximal third of the tibial shaft treated with intramedullary nails and blocking screws. J Orthop Trauma. 2001; 15:264-70.

14. Stedtfeld HW, Mittlmeier T, Landgraf P, Ewert A. The logic and clinical applications of blocking screws. J Bone Joint Surg Am. 2004; 86(2):17-25. 